\title{
THEORETICAL ANALYSIS OF CAUSES AND REVOLUTION FACTORS IN THE CONTEXT OF BEHAVIORISM
}

Удк 316. 332:64

DOI https://doi.org/10.32843/2663-

5208.2019.9.12

\section{Идрисов Б.}

к.соц.н.,

доцент кафедры социологии

Мелитопольский государственный педагогический университет имени

Богдана Хмельницкого

\begin{abstract}
Аналіз теорій революції та причин ії виникнення показує, що вивчення цього феномену відбувається вже тривалий період, а варіативність у застосуванні поняття відображає різноманіття наукових концептів у ранжуванні основних революційних причин $і$ фракторів. Подано класифрікацію різних теорій революції, яка складена за схожим ознаками, або як окремий френомен. Зазначено, що психологічний фрактор є найбільш притаманним нестабільним суспільствам, що впливає на розвиток революційної ситуації в суспільстві. На підставі концепції біхевіоризму виділено, що причиною української революції є трансорормація суспільної свідомості, вихідною умовою якої є соціальна дезорієнтація, що викликано зміною стратифрікаційного порядку та правилами дії соціального лісрту. Визначено, що основними фракторами змін у суспільній свідомості є соціальна аномія $і$ соціальний чинізм, які призводять до розвитку в суспільстві такого соціального фрактора, як соціальне безумство. Доведено, що негативна транссрормація суспільної свідомості проявляється: у розвитку ідей релігії, утопії, місру й міленарізму, що використовуються елітами в боротьбі за владу иляхом створення утопічної міфоологеми про справедливу форму управління державою; у руйнуванні колишньої системи моральних цінностей; у розвитку впевненості щодо неможливості позитивних інституційних змін чинної влади; у закликах про справедливість будь-яких революційних дій. Розглянуті причини і фрактори корелюються з протестним голосуванням й відображають розвиток в суспільстві нових міфрологем, що згодом призводить до розвитку нової революційної ситуації та повторення колишнього револючійного причинного взаємозв'язку.

Ключові слова: революційна ситуація, транссрормація суспільної свідомості, причинні взаємозв'язки революції.
\end{abstract}

The analysis of theories of the revolution and the causes of its emergence shows that the study of this phenomenon is a long period, and the variability in the application of the concept reflects the diversity of scientific concepts in ranking the main revolutionary causes and factors. The classification of different theories of revolution, which is composed on similar grounds, or as a separate phenomenon, is presented. It is noted that the psychological factor is the most characteristic of unstable societies, which influences the development of the revolutionary situation in society. Based on the concept of behaviorism, it is emphasized that the cause of the Ukrainian revolution is the transformation of social consciousness, the initial condition of which is social disorientation, which is caused by the change of the stratification order and the rules of action of the social lift. It is determined that the main factors of changes in social consciousness are social anomy and social cynicism, which leads to the development of a social factor such as social insanity in society. It is proved that the negative transformation of social consciousness manifests itself in the development of the ideas of religion, utopia, myth and millenaries, used by elites in the struggle for power by creating a utopian myths about a fair form of government; collapsing system of moral values; feelings about the impossibility of positive institutional changes in the current and voiced calls for the justice of any revolutionary action. The reason and factors considered are correlated with the protest vote and reflect the development of new myths in society, which subsequently leads to the development of a new revolutionary situation and the repetition of the former revolutionary causal relationship.

Key words: revolutionary situation, transformation of social consciousness, causal interconnection of revolution.
Постановка проблемы. Необходимость изучения революции обусловлена особенностями данного феномена - мобильностью структурных изменений за достаточно короткий промежуток времени. Периодически возникающие либо повторяющиеся революции в различных странах мира стали неотъемлемым элементом существования человечества на современном этапе развития, и соответственно, осознание причин революции и факторов их развития вызывает несомненный интерес социологов и исследователей в различных отраслях научного познания.

Анализ исследований и публикаций. Актуальность социологического изучения революции впервые выделил П. Сорокин в 1923 году, что дало импульс к развитию новой научной отрасли. Дальнейший интерес к проблеме получил свое отражение в исследованиях Т. Гарра, В. Вертхайма, Р. Дарендорфа, Т. Парсонса, Т. Скочпол, У. Сьюэлла, П. Штомпки, Ж.-Л. Фабиани и многих других зарубежных специалистов. Анализ отечественных исследований показывает, что вопросам революции посвящены работы таких социологов, как М. Антонович, В. Бурлачук, М. Гуцалюк, О. Журавлев, А. Колодий, Р. Рябчук, С. Сальникова. Однако, несмотря на большое количество научных публикаций, вопросы причин радикальных общественных 
изменений остаются недостаточно изученными, что вызвано:

1) отсутствием единого подхода к определению содержания понятия «революция» и, соответственно, ее причин;

2) разнообразием научных концептов в выделении революционных факторов, условий развития, хода событий и последствий революции.

Постановка задания. Именно поэтому целью статьи является выделение причины развития революционной ситуации в Украине в контексте бихевиоризма, а ее основными заданиями - анализ и классификация причин революции, и выделение ее социально-психологических факторов.

Изложение основного материала. В соответствии с поставленными задачами статьи следует выделить, что понятие «революция» обладает собственной историей развития и концептуальными различиями. Так, анализ работ, посвященных данному феномену, показывает, что у античного историка Полибия под «революцией» подразумевалась переустановка вещей в надлежащем порядке, где тирания - это отклонение, требующее исправления.

В Средневековье Н. Коперник слово «революция» использовал в астрономии, что означало вращение небесных тел по кругу.

Отметим, что трактовку понятия в современном контексте впервые использовал Н. Макиавелли в 1513 году в работе «Государь», и уже в текстах Ф. Бэкона, Д. Юма и Э. Берка под словом «революция» стали подразумеваться беспорядки, заговоры и мятежи, происходящие с древнейших времен по настоящее время.

В эпоху Просвещения проявились первые противоречия в применении понятия: например, Вольтер считал английскую революцию 1640 конфликтом между протестантами и католиками; у Монтескье революция трактуется как естественный процесс, итогом которого являются изменения в государственном устройстве; у Дидро - это значительное изменение в управлении государством, где одной из ключевых составляющих является движение масс; у Гегеля революция отличается от обычных реформ участием в ней народа, представляя собой массовое движение снизу.

B XIX веке изучение вопросов возникновения революции приобрело системный характер. Так, Дж. Кларк, в статье «История и теория революций», напечатанной в 1862 году, впервые выделяет, что «...Восстание и мятеж могут быть результатом прихоти, страсти, амбиций, ревности или других простых локальных причин, и именно поэтому они быстро проходят». Автор предложил несколько вариаций поня- тия «революция», отметив что «во всех определениях фундаментальная концепция одна и та же»:

1) радикальное или органическое изменение в устройстве государства, совершенное мирным либо насильственным путем;

2) успешное сопротивление существующей власти, в результате которого устанавливается ее новая форма;

3) исчезновение устаревших институтов власти и возникновение новых, определяющих движение в развитии истории [14, с. 4-5].

В данный период начинают формироваться теории, которые впоследствии станут основой практических революционныхдействий. Однако лишь после волны революций, произошедших в первой половине XX века, проявилась необходимость научного переосмысления причин кардинальных социальных изменений. Так, в работе «Социология революции», опубликованной в 1925 году и давшей импульс к развитию новой научной отрасли, П. Сорокин с позиции бихевиоризма рассматривает революцию как «определенное изменение поведения членов общества в психике и идеологии, убеждениях и верованиях, морали и оценках» [9].

Отметим, что в статье сознательно не приведен анализ современных понятий «революция», так как авторы многочисленных исследований данного феномена определяют его содержание в зависимости от личного ранжирования основных причин возникновения и факторов развития. Именно поэтому, по определению самого П. Сорокина, «не имеет смысла добавлять ко всем этим определениям еще одно дополнительное» [9].

Проведенный анализ научных работ показывает, что дальнейшие исследования революции проводились в следующих направлениях:

1) в контексте простого распределения революций на «западные» и «восточные», где причинами революции являются изменения социально-экономических формаций, либо революцией называются любые массовые радикальные формы протеста, мятежи и государственные перевороты;

2) сложного сочетания теорий, где рассматриваются различные типы, виды и подвиды революций, группируемые по схожим признакам и методам изучения, при этом основной целью социологических исследований в США является нахождение механизмов предотвращения революции.

Согласно направленности, теории революции группируются по схожим признакам и методам изучения:

1) концепции, рассматривающие влияние политических элит государства на развитие революционных процессов; 
2) экономические теории, определяющие влияние социально-экономического кризиса в управлении либо значение противоречий технологической модернизации на рост революционных настроений;

3) бихеовиористские теории, в которых изучаются вопросы массовой психологии.

В таблице 1 нами предлагается классификация наиболее признанных теорий революции, составленная по схожим выделенным в них причинам, либо как феномен, заслуживающий особого внимания [12, с. 65-68; 21, с. 199-257; 10 , c. $45-47,82 ; 18$, c. $415-419 ; 16$, c. $68-83$; 13 , с. $138-162 ; 15$, с. $133-163 ; 17 ; 22$, с. $1-17 ; 19]$. Отметим, что в представленную классификацию нами не включены теории «цветных революций» Д. Шарпа и «прогнозирования будущих революций» Дж. Форана по следующим причинам:

1) диссертацию Джина Шарпа 1964 года «Ненасильственные методы свержения режимов» сами американские ученые рассматривают как теорию свержения правительств, но не изучения причин революции, а работа «198 методов ненасильственных действий», изданная в 1973 году, является методическим пособием по созданию революционной ситуации в «недемократических» странах и практическим действиям революционеров;

2) исследования Джона Форана 1998-2008 годов, где ключевой является работа «Взять власть. О происхождении революций третьего мира» 2005 года издания, относятся к футурологической концепции, основанной на количественном историко-сравнительном анализе с использованием «таблицы истинности» Т. Викхам-Кроули.

Отметим, что практически во всех теориях отмечается, что психологический фактор наиболее присущ нестабильным обществам. Именно поэтому в статье рассматривается революционная ситуация как долгосрочная причина революции, сформировавшаяся под влиянием следующих факторов:

1) периодической трансформации общественного сознания;

2) развития в обществе идей утопии, мифа, религиозности и милленаризма в построении государства.

Решение задачи основано на утверждении П. Сорокина, что исходным условием

Таблица 1

\section{Причины революции, представленные в различных социологических концепциях}

\begin{tabular}{|c|c|c|}
\hline $\begin{array}{c}\text { Теории } \\
\text { революции }\end{array}$ & Авторы & Основные детерминанты кардинальных действий \\
\hline $\begin{array}{l}\text { Описания, } \\
\text { корреляции } \\
\text { и уникализма }\end{array}$ & $\begin{array}{l}\text { К. Бринтон, } \\
\text { Д. Фаирчайлд, } \\
\text { Р. Макивер }\end{array}$ & $\begin{array}{l}\text { Отсутствует понятие «причина»: описываются экономические, } \\
\text { социальные, психологические, культурные «корреляции» и } \\
\text { «переменные», характеризующие предреволюционную ситу- } \\
\text { ацию }\end{array}$ \\
\hline $\begin{array}{l}\text { Поссибилизма } \\
\text { и взаимодействия }\end{array}$ & $\begin{array}{l}\text { В. Вертхайм, } \\
\text { Л. Стоун }\end{array}$ & $\begin{array}{l}\text { Взаимодействие интеллектуального, экономического, } \\
\text { политического, социального и психологического факторов }\end{array}$ \\
\hline $\begin{array}{l}\text { Утопии и мифа, иде- } \\
\text { ологизма и милле- } \\
\text { наризма }\end{array}$ & $\begin{array}{l}\text { С. Ейзенштадт, } \\
\text { М. Ласки, } \\
\text { Г. Колли } \\
\text { и Л. Миллер, } \\
\text { Р. Блакей }\end{array}$ & $\begin{array}{l}\text { Апелляция к «справедливой» форме правления; дискредита- } \\
\text { ция системы ценностей, на которую опирается старая власть; } \\
\text { милленаристский призыв современных «пророков» К людям с } \\
\text { разорванными традиционными связями }\end{array}$ \\
\hline $\begin{array}{l}\text { Автономности поли- } \\
\text { тического фактора }\end{array}$ & $\begin{array}{l}\text { В. Тимашев, } \\
\text { С. Хантингтон, } \\
\text { Дж. Джиллис }\end{array}$ & $\begin{array}{l}\text { Напряженность и конфликт между правительством и оппо- } \\
\text { зицией, вызванные социальными, экономическими и нацио- } \\
\text { нальными факторами, где свершение революции зависит } \\
\text { исключительно от особенностей существующей политической } \\
\text { системы }\end{array}$ \\
\hline $\begin{array}{l}\text { Сила оппозиции или } \\
\text { «Теория насилия» }\end{array}$ & П. Калверт & $\begin{array}{l}\text { Превышение у оппозиции «минимального количества силы, } \\
\text { необходимой для свержения правительства в данный момент» }\end{array}$ \\
\hline Внутренней войны & Х. Экштейн & $\begin{array}{l}\text { Неэффективность элит в формулировке новых политических } \\
\text { ориентаций; препятствование и подрывная деятельность } \\
\text { оппозиции действиям правящей элиты }\end{array}$ \\
\hline $\begin{array}{l}\text { Социального } \\
\text { конфликта }\end{array}$ & $\begin{array}{l}\text { ч. Джонсон, } \\
\text { Д. Пейдж }\end{array}$ & $\begin{array}{l}\text { Дисфункция общественной системы; коммерческая пере- } \\
\text { стройка социума; рост неравенства в перераспределении } \\
\text { конечного продукта }\end{array}$ \\
\hline Монизма & $\begin{array}{l}\text { К. Маркс, Г. Уайт, } \\
\text { И. Крэмник, } \\
\text { М. Олсон, }\end{array}$ & $\begin{array}{l}\text { Противодействие устаревших систем управления созданию } \\
\text { взаимосвязи между экономическими, технологическими и } \\
\text { социальными изменениями в развитии общества }\end{array}$ \\
\hline $\begin{array}{l}\text { Структуралистских } \\
\text { моделей новых } \\
\text { революций }\end{array}$ & Т. Скокпол & $\begin{array}{l}\text { Слабость государства на международной арене; экономиче- } \\
\text { ское отставание; взаимосвязь государства с доминирующим } \\
\text { классом, где используются ресурсы всего общества для } \\
\text { достижения собственных целей }\end{array}$ \\
\hline
\end{tabular}


революции является разбалансированность социальной или культурной систем либо их обоих в совокупности, влияющих на деформацию общественного сознания. Подобный подход позволяет сделать предположение, что украинское общество с момента обретения государственной независимости испытывает определенные повторяющиеся периоды трансформации общественного сознания, состоящие из трех фаз, последовательно сменяющих друг друга.

Выделим, что исходным условием подобной трансформации является социальная дезориентация - состояние, проявляемое в низкой чувствительности к социальным нормам и непонимании личностью их иерархии. Так, произошедшая в 1991 году смена общественно-экономической формации привела не только к перераспределению общественного богатства в пользу меньшинства и обнищанию подавляющей части населения, но и к уничтожению прежнего стратификационного порядка, разрушению устоявшихся культурных норм и правил действия социального лифта. Дальнейшее кризисное развитие ситуации в начале 1990-х годов привело к такому состоянию общества, когда, по утверждению П. Сорокина, «индивид отказывается от цивилизованного поведения. <...> Законопослушный гражданин становится вором и бандитом, работник становится нищим, аристократ отправляется на рынок торговать [9].

1. Фаза социальной аномии - состояние общества, характеризующееся формированием «аморального большинства» в первой половине 1990-х годов. По результатам исследований Института социологии НАНУ Е. Головаха делает вывод, что «Действовавшие ранее нормы человеческой порядочности и ответственности, регулирующие поведение и взаимоотношения людей начинают восприниматься большинством как нормы поведения «моральных аутсайдеров». Возникший при этом конфликт между необходимостью в авторитетном институте общественной морали и пренебрежением к нему со стороны «аморального большинства» будет только развиваться» [3, с. 20-22]. Р. Мертон в работе «Социальная теория и социальная структура» приходит к выводу о взаимосвязи между ростом аномической деморализованности и агрессивными настроениями в обществе [8, с. 118-124]. Таким образом, состояние социальной аномии приводит к развитию социального цинизма, вызванного ненормативной реакцией на аномию и сопровождающегося последовательным разрушением моральных основ регуляции социального поведения.

2. В фазе социального цинизма в общественном сознании происходит, по утверждению Е. Головахи, «Разрушение социального капитала, являющегося решающим фактором роста общественного благосостояния и перспективой устойчивого развития социума. Да и о каком социальном капитале можно говорить в государстве, где граждане открыто соглашаются с суждениями, характеризующими большинство людей как бесчестных, непорядочных и не заслуживающих доверия. Оценка большинством большинства, по сути, означает общественную самооценку, которая не зависит от уровня образования и рода занятий» [4, с. 59-66]. Соответственно, сформировавшееся «аморальное большинство» избирает себе подобную элиту государственного управления, которая для укрепления собственной власти различными способами активно выстраивает «аморальный порядок», например, по линии «галицкой» либо «донецкой» моделей электорального выбора, все более и более раскалывая общество [7, с. 142-152].

3. Фаза социального безумия характеризуется активным разрушением остатков прежней ценностно-нормативной системы, вследствие чего проявляются следующие элементы деформации общественного сознания:

1) в поведении начинают превалировать аффективный, когнитивный и моральный аспекты индивидуального сознания;

2) повторяющаяся смена моральных ценностей приводит к неопределенности личности в выборе целей, методов и средств повышения собственного социального статуса.

Сложившаяся ситуация в обществе напрямую влияет на формирование такого образа жизни, в результате чего в индивидуальном сознании возникает противоречие между поступками и эмоциями. При этом собственные рациональные действия по адаптации к изменяющимся условиям жизни человек эмоционально отторгает, демонстрируя постоянное ухудшение социального самочувствия [3, с. 20-22]. Дальнейшие изменения в общественном сознании начинают проявляться в массовом искажении восприятия, памяти и логической связи идей, в подверженности иллюзиям и суевериям, на что обратил внимание еще в 1923 году П. Сорокин [9]. Подобное болезненное состояние общества, где эмоциональное превалирует над рациональным, может достаточно долго оставаться локальным явлением. Однако оно может привести и к несопоставимым по масштабам воздействия на общественную жизнь социопатиям, например, вооруженному конфликту внутри страны [6, c. 6-12].

Именно в данной фазе, психологическая нестабильность общества начинает активно использоваться элитами в качестве основного ресурса в борьбе за власть. За достаточно короткий промежуток времени под влиянием 
подконтрольных СМИ в обществе создаются следующие факторные взаимосвязи развития революционной ситуации:

1) формируется утопическая мифологема о «справедливой форме» управления государством;

2) дискредитируется прежняя система ценностей, поддерживаемая действующей властью;

3) развиваются настроения о невозможности позитивных институциональных изменений действующей политической элитой в ближайшем будущем - складывается ситуация, когда «революционный импульс следует считать производным от фрустрации» [20, c. 233];

4) современными «пророками» озвучиваются милленаристские призывы о справедливости любых революционных действий, направленные на людей с разорванными социальными связями;

5) выделяются священное и профанное, определяются методы инициации масс и выбор жертвы, выбираются пространство и время ритуала перехода власти. Данный механизм достаточно подробно описан В. Бурлачуком в работе «Власть, ритуал и «Оранжевая революция» [1, с. 63-75].

Однако стремление людей воплотить мечту о лучшем обществе, избирая новую элиту управления государством, приводит к повторению революционной причинной взаимосвязи, выделенной М. Ласки: «утопия революция - догма - ложь - возвращение к утопии - новая революция, где каждый революционер впоследствии становится либо угнетателем, либо еретиком» [18, с. 415-419].

Выводы из проведенного исследования. Таким образом, полученные результаты исследования дают основания для выводов, что долгосрочной причиной украинских революций является революционная ситуация, сформированная под влиянием следующих факторов:

1) трансформация общественного сознания, представляющая собой следующую взаимосвязь трех звеньев-фаз: социальная аномия - социальный цинизм - социальное безумие, где каждая фаза является логическим следствием и продолжением предыдущей, обладает тенденцией к повторению и характеризуется сужением во времени - первый революционный период продолжался 13 лет (1991-2004) и закончился «Оранжевой революцией»; второй занял 9 лет (2004-2013), завершившись «Революцией достоинства»;

2) развитие в обществе идей утопии, мифа, религиозности и милленаризма в построении справедливого государства.

Данные причина и факторы влияют на сохранение революционной ситуации, кор- релируются с протестным голосованием, вызванным фрустрацией, и отражают развитие в обществе новой мифологемы о «преданном слуге, служащем своему народу».

Следует отметить, что в статье рассмотрен лишь бихевиористкий аспект революций исследования революции конца XX - начала XXI столетий направлены на комплексное изучение причин и факторов, так как «социальные причины» могут коррелировать с демографическим фактором, а «поведение элит» находиться в экономической плоскости. Однако для более детального анализа необходимо изучение экономического, политического, военного и культурного факторов, в том числе и влияние внешних акторов на внутреннюю политику государства. Поэтому вопросы сохранения революционной ситуации и свершения новых революций в Украине требуют комплексного изучения учеными различных отраслей науки.

\section{ЛИТЕРАТУРА:}

1. Бурлачук В. Власть, ритуал и «Оранжевая революция». Соціологічне знання та влада: суперечливі взаємовідносини соціологічних досліджень i політичної практики. Київ : Стилос: Фоліант, 2005. C. 63-75.

2. Голдстоун Дж. Революции. Очень краткое введение. Москва : Институт Гайдара, 2015. 192 с.

3. Головаха Е. Феномен «аморального большинства» в постсоветском обществе: транссрормация массовых представлений о нормах социального поведения в Украине. Мониторинг общественного мнения: экономические и социальные перемены. Киев, 2002. № 6 (62). С. 20-22.

4. Головаха $€$. Соціальний цинізм і аномія в українському суспільстві: загальна динаміка і останні зміни. Українське суспільство: моніторинг соціальних змін. Київ, 2014. Вип. 1(1). С. 49-56.

5. Дарендорф Р. Современный социальный консрликт. Очерк политики свободы. Москва : РОССПЭН, 2002. 288 с.

6. Ідрісов Б. Трансорормація суспільної свідомості як довгострокова причина революції. Соціологічні студії: зб. наук. праць. Луцьк : Вид. Східноукраїнського університету ім. Лесі Українки, 2019. 1(14). C. 6-12.

7. Идрисов Б. Типология и моделирование электоральной культуры в современном украинском обществе. Нова парадигма : зб. наук. праць. Київ : Вид-во НПу ім. М.П. Драгоманова, 2011. Вип. 101. С. 142-152.

8. Мертон Р. Социальная теория и социальная структура. Социальная структура и аномия. Москва : Социс, 1992. № 2-4. С. 118-124.

9. Сорокин П. Социология революции. Москва : PОССПЭН, 2005. 704 c. URL: https://platona.net/load/ knigi_po_filosofii/sociologija/sorokin_p_sociologija_ revoljucii_2005/25-1-0-4696.

10. Эйзенштадт Ш. Революция и преобразование обществ. Сравнительное изучение цивилизаций. Москва : Аспект Пресс, 1999. 416 с. 


\section{ГАБІТУС}

11. Brinton C. The Anatomy of Revolution. New York: Vintage, 1965. 320 p. http://mrfarshtey.net/review/ Political_Revolutions.pdf.

12. Calvert P. Revolution and international politics. London : Bloomsbury Academic, 2016. 176 p.

13. Clark J. The History and Theory of Revolutions. Leopold Classic Library, 2015. September, 28. 43 p. URL: https://www.amazon.com/history-theory-revolutions-Princenton-Review/dp/B015W801QM.

14. Eckstein $\mathrm{H}$. On the Etiology of Internal Wars. History and Theory, 1965. Vol. 4. № 2. Pp. 133-163. URL: https://philpapers.org/rec/ECKOTE.

15. Huntington S. Why International Primacy Matters. International Security, 1993. Vol. 17. №. 4. Pp. 68-83. URL: https://inis.iaea.org/search/search. aspx?orig_q=RN:25003789.

16. Johnson C. Revolutionary Change. - Boston : Little, Brown, 1966. 169 p. URL: https://books.google.com.ua/ books/about/Revolutionary_Change.html?id=LYmfmDa6MUEC\&redir_esc=y.
17. Lasky M. Utopia \& Revolution. Western Ontario: Political Theory, 1977. № 5 (3). Pp. 415-419. URL: https://refdb.ru/look/1516350-pall.html.

18. Skocpol T. France, Russia, China: A Structural Analysis of Social Revolutions. Harvard Universitet, 1976. 210 c. URL: https:// pdfs.semanticscholar.org/7fed/fe91707a1ad78f5b 4d7d50763fce12ea3eb6.pf.

19. Waelder R. Progress and Revolution: A Study of the Issues of Our Age Progress. N.-Y. : International Universities Press, 1967. $372 \mathrm{p}$.

20. Wertheim W. Evolution and Revolution: The Rising Waves of Emancipation. Harmondsworth : Penguin Books Ltd.,1974. 416 p.

21. White H. Stories from Identity and Control. Bologna: Sociologica Fascicolo, 2007. 3, novembredicembre. Pp. 1-17. URL: http://citeseerx.ist.psu.edu/ viewdoc/download?doi=10.1.1.893.9171\&rep=rep1\& type=pdf. 